\title{
Diferentes aspectos da resposta imunológica na COVID-19
}

\author{
Different aspects of the immune response in COVID-19 \\ Diferentes aspectos de la respuesta inmune en COVID-19
}

Recebido: 29/10/2021 | Revisado: 04/11/2021 | Aceito: 05/11/2021 | Publicado: 08/11/2021

\author{
Ana Alice Reis dos Santos \\ ORCID: https://orcid.org/0000-0001-8476-0266 \\ Universidade Anhembi Morumbi, Brasil \\ E-mail: analicereis10@hotmail.com \\ Karen Kaori Onishi de Paula \\ ORCID: https://orcid.org/0000-0002-8622-582X \\ Universidade Anhembi Morumbi, Brasil \\ E-mail: karen.onish42@gmail.com \\ Bruno Fernando Daneli Marasco \\ ORCID: https://orcid.org/0000-0002-5549-7814 \\ Universidade Anhembi Morumbi, Brasil \\ E-mail: brunomarasco@hotmail.com \\ Daniele Gonçalves Castilho \\ ORCID: https://orcid.org/0000-0002-6936-7674 \\ Universidade Anhembi Morumbi, Brasil \\ E-mail: daniele.unifesp@gmail.com
}

\begin{abstract}
Resumo
Durante a pandemia da COVID-19, infecção pelo vírus SARS-CoV-2, o qual provoca síndrome respiratória grave. Diferente de outras infecções virais, sua resposta a inflamação diverge do comum, assim se tornou um enigma para compreender o funcionamento celular durante a resposta imunológica. Sendo assim muitos estudos permitiram iniciar a elucidação a partir das células principais, TCD4, TCD8, Linfócitos B e Anticorpos. Esta revisão tem como objetivo buscar em artigos e pesquisas cientificas relacionadas ao tema, via bases de dados como: Google Scholar, Elsevier, PubMed, Medline, The New England Journal of Medicine e Scielo, textos relacionados às características gerais do COVID-19 e a imunologia relacionada à infecção pelo vírus SARS-CoV-2. Embora mais estudos sejam necessários, uma imagem começou a emergir que revela que Células TCD4 +, células TCD8 + e anticorpos neutralizantes, contribuem para o controle de SARS-CoV-2 em ambos os casos não hospitalizados e hospitalizados de COVID-19. As funções específicas e cinética destes adaptativos as respostas imunes são discutidas, bem como sua interação com a imunidade inata e implicações para COVID-19 vacinas e memória imunológica contra reinfecção, deve-se lembrar que mesmo com as conclusões supracitas, hoje existem variantes do vírus, as quais fazem repensar sobre a eficácia da imunidade de rebanho e imunidade geral, pois elas podem ser mais transmissíveis e mais resistentes a vacinas. Sendo assim ressaltamos a importância de manter os cuidados relacionados a higiene e proteção, seguindo o recomendado pelas agências de saúde mundiais.
\end{abstract}

Palavras-chave: Imunologia do Covid-19; Resposta imune adquirida; Tempestade de citocinas; Infecção viral.

\begin{abstract}
During the COVID-19 pandemic, infection by the SARS-CoV-2 virus, which causes severe respiratory syndrome. Unlike other viral infections, its response to inflammation diverges from the usual, thus becoming an enigma to understand the cellular function during the immune response. Thus, many studies have started to elucidate the main cells, TCD4, TCD8, B lymphocytes and antibodies. This review aims to search in articles and scientific research related to the subject, via databases such as Google Scholar, Elsevier, PubMed, Medline, The New England Journal of Medicine and Scielo, texts related to the general characteristics of COVID-19 and the immunology related to infection by the SARS-CoV-2 virus. Although more studies are needed, a picture has begun to emerge that reveals that TCD4 + cells, TCD8 + cells and neutralizing antibodies, contribute to the control of SARS-CoV-2 in both non-hospitalized and hospitalized cases of COVID-19. The specific functions and kinetics of these adaptive immune responses are discussed, as well as their interaction with innate immunity and implications for COVID-19 vaccines and immunological memory against reinfection. Thus, we emphasize the importance of maintaining the care related to hygiene and protection, following the recommendations of world health agencies.
\end{abstract}

Keywords: Covid-19 immunology; Acquired immune response; Cytokine storm; Viral infection.

\section{Resumen}

Durante la pandemia de COVID-19, la infección por el virus SARS-CoV-2, que provoca un síndrome respiratorio grave. A diferencia de otras infecciones víricas, su respuesta inflamatoria difiere de las normales, lo que la convierte 
en un enigma para comprender la función celular durante la respuesta inmunitaria. Por ello, muchos estudios han comenzado a dilucidar las células clave, TCD4, TCD8, linfocitos B y anticuerpos. El objetivo de esta revisión es buscar artículos e investigaciones científicas relacionadas a través de bases de datos como Google Scholar, Elsevier, PubMed, Medline, The New England Journal of Medicine y Scielo en busca de textos relacionados con las características generales del COVID-19 y la inmunología relacionada con la infección por el SARS-CoV-2. Aunque se necesitan más estudios, ha empezado a surgir un panorama que muestra que las células TCD4+, las células TCD8+ y los anticuerpos neutralizantes contribuyen al control del SARS-CoV-2 tanto en los casos no hospitalizados como en los hospitalizados de COVID-19. Se discuten las funciones específicas y la cinética de estas respuestas inmunitarias adaptativas, así como su interacción con la inmunidad innata y las implicaciones para las vacunas contra COVID-19 y la memoria inmunológica contra la reinfección. Por ello, insistimos en la importancia de mantener la higiene y los cuidados de protección, siguiendo las recomendaciones de los organismos sanitarios mundiales

Palabras clave: Inmunología de Covid-19; Respuesta inmune adquirida; Tormenta de citoquinas; Infección viral.

\section{Introdução}

Atualmente, vivemos uma pandemia causada por um vírus pertencente à família Coronaviridae, o qual foi nomeado em 12 de janeiro de 2020 pela Organização Mundial da Saúde O.M.S. como “novo coronavírus 2019” (2019-nCoV). (OMS, 2020). Esse vírus causa uma doença sistêmica e os indivíduos apresentam diferentes espectros da doença, desde casos assintomáticos a casos mais graves, como a síndrome respiratória aguda. Análises genômicas de diversos coronavírus conhecidos possibilitaram nomear o vírus responsável pela pandemia de SARS-CoV-2. (Naqvi, et al., 2020). O conhecimento sobre o vírus e sua interação com o hospedeiro são fundamentais para o combate do SARS-CoV-2. Vírus estruturalmente semelhantes ao SARS-CoV-2, como o SARS (Severe Acute Respiratory Syndrome) e o MERS (Middle East Respiratory Syndrome) também acometem animais e humanos e são importantes modelos de estudo. (Zhu et al., 2020). O desenvolvimento de estratégias de intervenção eficazes depende do conhecimento dos mecanismos moleculares e celulares relacionados com o processo infeccioso, o que destaca a importância de estudar as interações vírus-hospedeiro no nível molecular, na tentativa de identificar alvos para intervenção farmacológica e elucidar fatores, tanto virais como do hospedeiro, que são decisivos para o desenvolvimento de casos graves das doenças. (V'Kovski et al., 2020). A resposta imunológica é um dos fatores importantes que determina o curso da doença. Neste contexto, sabendo que uma resposta imune efetiva é importante para o controle e eliminação de quase todas as infecções virais, é fundamental elucidar os mecanismos do sistema imunológica para eliminação efetiva do SARS-CoV -2.

\section{Metodologia}

Realizamos uma revisão da literatura sobre a infecção causada por SARS-CoV-2 utilizando as bases de dados Google Scholar, Elsevier, PubMed, Medline, The New England Journal of Medicine, Scielo e livros relacionados ao tema, para que fosse possível desenvolver um artigo original. Sendo assim encontramos os artigos mais adequados junto ao objetivo da pesquisa, se tornar multiplicador de informações em âmbito nacinal a respeito dos aspectos imunologicos da COVID-19. A maior fonte de dados foram artigos publicadas on-line pois em decorrência do tema escolhida e sua atualidade as informações e pesquisas então em constante mudança e modificação. Com base nisso utilizamos os seguintes termos em inglês: immunity inflammation, pandemic COVID-19, lung disease COVID-19, structure of COVID-19 e origin and evolution coronavirus, ao pesquisar em português os mesmos termos foram traduzidos

Os critérios de seleção dos artigos encontrados nesta revisão narrativa são os seguintes: o texto contém as características gerais do COVID-19 e a imunologia relacionada à infecção pelo vírus SARS-CoV-2. Sendo assim, através da revisão foi possível descrever os aspectos esperados, por meio da discussão e contextualização sobre os pontos da imunologia do COVID-19. 
Este método foi idealizado com auxilio da literatura: Manual de artigo de Revisão de Literatura, Vol. II (Gonçalves et al, 2021)

Os anos de publicação dos materiais utilizados como fonte para criação do trabalho podem ser conferidos na Figura 1.

Figura 1: Representação do ano de publicação dos materiais pesquisados.

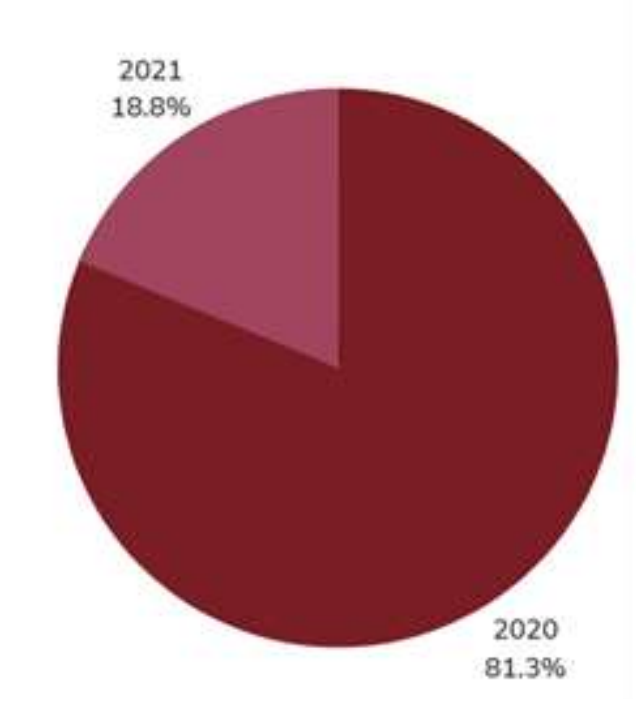

Fonte: Autores.

\section{Resultados e Discussão}

\subsection{Coronavírus}

Os coronavírus pertencem a família Coronaviridae e a subfamília Coronavirinae, onde possui quatro gêneros: Alphacoronavirus, Betacoronavirus, Gammacoronavirus e Deltacoronavirus. Eles infectam humanos, outros mamíferos e aves, e alguns animais domésticos. Contudo o coronavírus que infecta humanos, como HCoV-229E e HCoV-OC43, circulam a anos entre a população, incluindo os mais recentes identificados HCoV-NL3 e HCoV-HKU1, podendo causar geralmente leves infecções no trato respiratório associadas a sintomas comuns de resfriado. As infecções pelo SARS-CoV, MERS-CoV e SARS-CoV-2, que surgiram na população nos últimos 20 anos são altamente patogênicos. Ao infectar células epiteliais brônquicas, pneumócitos e células do trato respiratório superior em humanos, as infecções podem evoluir para patologias respiratórias graves com irreversíveis lesões pulmonares (V’Kovski et al., 2020).

O SARS-CoV-2 é um vírus de RNA fita simples positivo envelopado (Ceravolo, 2020). O seu genoma possui menos de 30.000 nucleotídeos; próximo a extremidade 5' a sequência de nucleotídeo codifica para diversas proteínas, dentre elas 16 proteínas não estruturais (nsps) que estão relacionadas com a replicação do genoma viral; próximo a exterminada 3' a sequência de nucleotídeos codifica 4 proteínas estruturais do vírus (proteína S, M, E e N) e outras proteínas acessórias (Mousavizadeh et al., 2020). 
Figura 2: Organização genética do SARS-CoV-2.

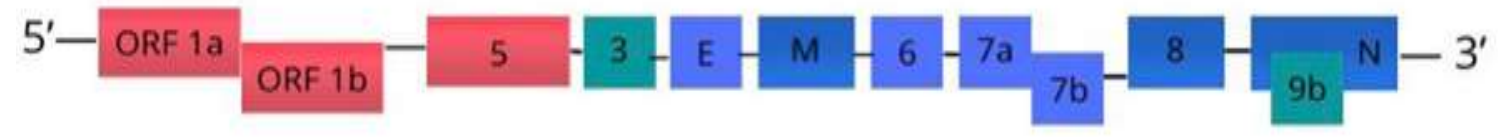

Fonte: Adaptado de Sin-Yee, et al. (2020): Esquema do genoma de RNA de fita simples de polaridade positiva (+ ssRNA) de SARS-CoV-2. Em direção à extremidade 5', o gene da replicase viral é codificado por meio de ORF la e ORF 1 b para a tradução das poliproteínas ppla e pp1ab. Em direção à extremidade 3 ', os genes das 4 proteínas estruturais principais $(S),(M),(E)$ e $(N)($ em verde) e os das proteínas acessórias (em azul) são codificados.

A proteína do núcleocapsídeo $(\mathrm{N})$ produz o capsídeo fora do genoma, onde ainda é embalado por um envelope que está associado a três proteínas estruturais: proteína de membrana (M), proteína Spike (S) e proteína envelope (E) e as demais dezesseis proteínas não estruturais (nsp1 à 16) (Naqvi et al., 2020). O SARS-CoV-2 infecta as células epiteliais do trato respiratório, os quais estão envolvidos em diferentes aspectos da patologia e transmissão do vírus.

\subsection{Resposta imune à infecções virais}

A imunidade inata de ação rápida e inespecífica, inicia-se a partir da entrada do vírus na célula. As células dendríticas são responsáveis pela ativação dos linfócitos T nos linfonodos e as células natural killer (NK) são uma importante linha de defesa para eliminação de células infectadas. A resposta imune inata é extremamente importante para ativar a resposta imune adaptativa. (Sette et al., 2021). A imunidade adaptativa é adquirida a partir do contato com um patógeno específico, e uma das características principais é a especificidade, além da geração de células de memória. (Gleichmann, 2020). A imunidade adaptativa contra os antígenos virais ocorre com a ativação da resposta imune celular mediada por linfócitos TDC $8^{+}$, as quais exercerão citotoxicidade ao reconhecer os antígenos virais nas células-alvo.

Na infecção por SARS-CoV-2 a resposta imune do hospedeiro é decisiva para a evolução da doença. O padrão da resposta imune tem sido associada a um maior número de internações em unidades de terapia intensiva (UTI) e mortalidade no COVID-19. Altas concentrações de fator estimulador de colônia de granulócitos (G-CSF), proteína induzida por interferon gama 10 (IP10), proteína quimioatraente de monócitos 1 (MCP1), proteína inflamatória de macrófagos 1alfa (MIP1A) e fator de necrose tumoral alfa (TNF- $\alpha$ ) em comparação com pacientes fora da UTI foram relatados em pacientes com COVID-19. Em outro estudo, níveis mais elevados de receptor de interleucina-2 (IL-2), interleucina-6 (IL-6), interleucina-8 (IL-8), interleucina-10 (IL-10) e TNF- $\alpha$ foram encontrados em pacientes falecidos com COVID-19 em comparação com pacientes que se recuperaram da doença. Essas reações imunológicas observadas na COVID-19 grave podem caracterizar a tempestade de citocinas que está associada a consequências clínico-patológicas desfavoráveis. (Mahmudpour et al., 2020). A tempestade de citocinas é uma liberação descontrolada de citocinas que foi observada em algumas doenças infecciosas e não infecciosas, levando a uma condição de hiperinflação no hospedeiro (Brandão et al., 2020). As citocinas podem ser positivas promovendo a progressão benigna da doença, atuando na modulação de processos inflamatórios e podem facilitar o reparo de tecidos, mas, em alguns casos, determinadas citocinas podem ser utilizadas como biomarcadores que predizem casos severos da COVID-19.

Os humanos produzem anticorpos específicos para SARS-CoV-2, células TCD4 ${ }^{+}$, e células TCD8 ${ }^{+}$, os possuem papéis protetores no controle de infecções virais, porém a importância dos componentes da imunidade adaptativa varia dependendo da infecção viral. Em algumas infecções, um dos três ramos da imunidade adaptativa é criticamente importante para o controle da infecção viral e sobrevivência do hospedeiro. Para outras infecções virais, existe muita sinergia e redundância entre os ramos da imunidade adaptativa, resultando em mais caminhos para o controle de uma infecção e 
imunidade robusta. Por essas razões, é importante medir células TCD4 ${ }^{+}$específicas do antígeno, células TCD8+ e anticorpos nos mesmos indivíduos. (Naqvi et al., 2020)

Avaliando separadamente a quantidade de linfócitos T (TCD4 e TCD8), no período de infecção, conseguimos avaliar a importância da ação dos linfócitos, para evitar o risco de infecção aguda, o que pode ocasionar morte (Figura 3).

Figura 3: Modelo de trabalho integrado de imunologia COVID-19 e gravidade da doença.
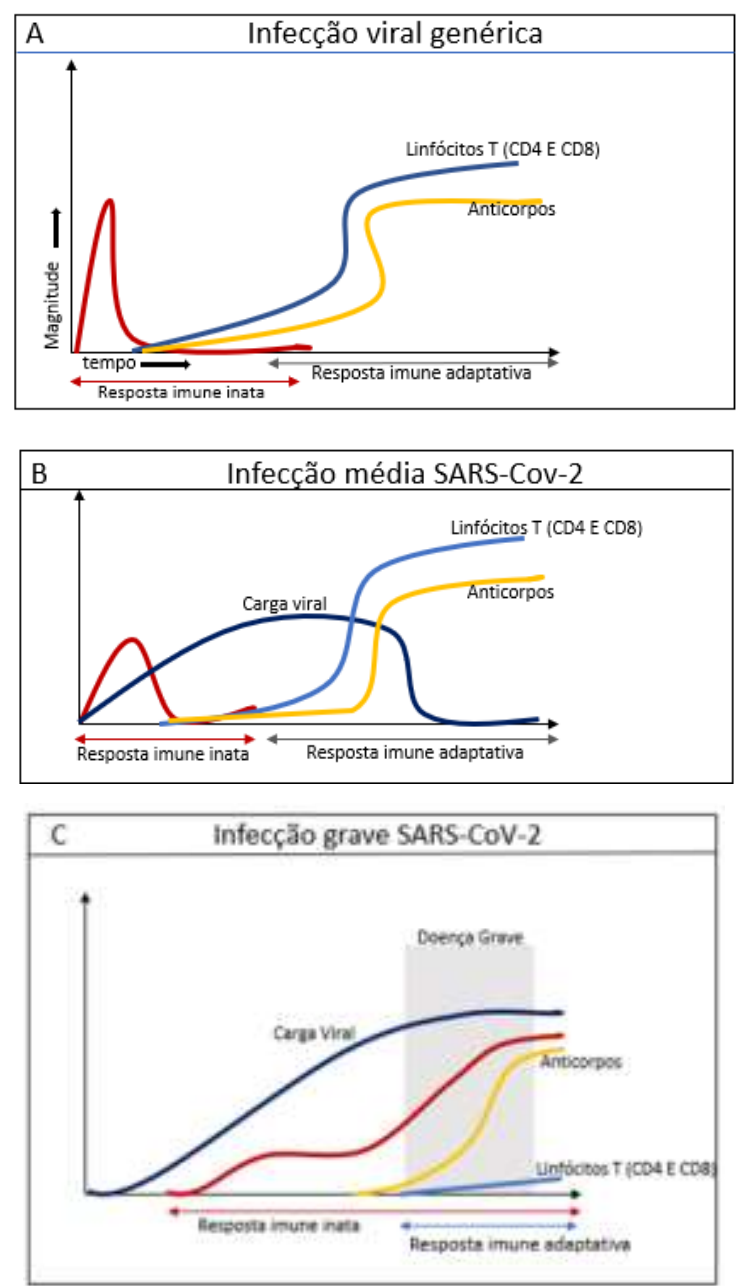

Adaptado de: (Sette et al., 2021): Trajetórias de resposta imune em COVID-19. Esquemas conceituais da cinética das respostas imunes ao SARS-CoV-2 sob condições de COVID-19 média (casos não hospitalizados) e COVID-19 grave ou fatal. A linha "Imunidade inata" refere-se especificamente à cinética de pico de citocinas e quimiocinas inatas detectáveis no sangue; as respostas imunes inatas ocorrem localmente durante o curso de uma infecção. "Células T" referese a células $\mathrm{TCD}^{+}$e $\mathrm{CD}^{+}$específicas de vírus. "Anticorpos" refere-se a anticorpos neutralizantes específicos para vírus. As setas indicam um ponto de tempo com diferenças importantes na presença ou ausência de respostas de células Te a magnitude da carga viral, comparando (B) e (C). (A) Um exemplo de infecção viral genérica; (B) Infecção média por SARS-CoV-2; (C) Infecção grave ou fatal por SARS-CoV-2. O período de doença clínica COVID-19 grave é sombreado em cinza.

O vírus SARS-CoV-2 retarda o desencadeamento de respostas imunes inatas intracelulares associadas a INFs tipo I e II. Sendo assim, a replicação viral segue acontecendo o que impede a ativação de uma resposta imune inata. Em um caso médio de COVID-19, um modelo simples é que o atraso temporal nas respostas imunes inatas é suficiente para resultar em infecção assintomática ou leve (sem hospitalização). (Oran et al., 2020). A presença de células T em indivíduos com COVID19 é sinal de que a resposta a infecção é efetiva, e em indivíduos com infecção grave percebe-se uma menor prevalência de células $\mathrm{T}$, sendo assim as respostas das células $\mathrm{T}$ podem ser importantes para o controle e resolução de uma infecção primária por SARS-CoV-2, acompanhada por imunopatologia celular inata e uma assinatura de citocina plasmática de CXCL10 elevado, interleucina (IL) -6, e IL-8. O risco de uma resposta imune inata inicial pobre ao SARS-CoV-2 é destacado pelos 
achados surpreendentes de risco muito alto de COVID-19 grave ou fatal em indivíduos com respostas de IFN tipo I defeituosas (Aid et al., 2020).

Se o atraso da resposta imune inata for muito longo, devido à evasão particularmente eficiente pelo vírus, imunidade inata defeituosa ou uma combinação de ambos, então o vírus obtém uma grande vantagem na replicação no trato respiratório superior e pulmões, e falha em preparar uma resposta imune adaptativa por um longo tempo, resultando em condições que levam a doenças pulmonares graves o suficiente para hospitalização. Este achado é consistente com muitos estudos que encontraram características inatas de citocinas/quimiocinas de imunopatologia, especialmente a observação de neutrófilos no sangue e um grande número de neutrófilos nos pulmões estão associados a doença COVID-19 em estágio final grave. Em contraste, a doença em estágio terminal geralmente não está relacionada à abundância preferencialmente elevada de células $\mathrm{T}$ no tecido pulmonar, consistente com o modelo assim. A resposta imune adaptativa é muito benéfica, e a resposta imune adaptativa tardia é tarde demais. (Li et al., 2020).

Células $\mathrm{T}$ foram encontradas em quase todas as respostas contra o SARS-CoV-2, os linfócitos TCD4 ${ }^{+}$são encontradas em maior quantidade, sendo identificados como um grupo de células essenciais para o controle primário da infecção. As células $\mathrm{T}$ específicas, são relevantes para imunidade protetora, inclusive contra a proteína Spike, além disso a indução de anticorpos anti-Spike depende dos linfócitos $\mathrm{TCD}^{+}$. Em um estudo examinando a resposta mediada por linfócitos $\mathrm{TCD}^{+}$para todas as proteínas SARS-CoV-2, foram detectados linfócitos TCD4 ${ }^{+}$contra quase todas as proteínas SARS-CoV-2 dentro da coorte em questão, com respostas de linfócitos $\mathrm{TCD}^{+}$indetectáveis apenas para a menor das proteínas. A prevalência e magnitude das respostas dos linfócitos TCD4 ${ }^{+}$contra o SARS-CoV-2 se correlacionam com o nível de expressão de cada proteína SARS-CoV-2. As proteínas Spike, M e nucleocapsídeo são os alvos mais proeminentes dos linfócitos TCD4+ específicas para SARS-CoV-2, mesmo assim foi encontrado resposta contra ORF3 e nsp3. (Grifoni et al., 2020).

$\mathrm{Na}$ infecção aguda os linfócitos TCD4 ${ }^{+}$tem a capacidade de se diferenciar em uma variedade de tipos de células auxiliares e efetoras, com capacidade de instruir os linfócitos B, ajudar os linfócitos TCD8 ${ }^{+}$, reestruturar a resposta imune inatas, ter atividades antivirais diretas e facilitar a reparação de tecidos. Além de comumente se diferenciam em linfócitos efetores Th1 e linfócitos T auxiliares foliculares (cTfh), os linfócitos efetores Th1 possuem atividades antivirais por meio da produção de IFN $\gamma$ e citocinas relacionadas. Linfócitos TCD8 ${ }^{+}$são essenciais para a eliminação de infecções virais, devido à sua capacidade de eliminar células infectadas, a presença de linfócitos $\mathrm{TDC} 8^{+}$especificas está relacionada melhoras nos quadros de COVID-19. Os linfócitos Th1 são importantes para aumentar a atividade dos linfócitos citotóxicos pela secreção do IFN $\gamma$. Thf auxiliam os linfócitos B e são essenciais para o desenvolvimento da maioria dos anticorpos neutralizantes e para imunidade humoral de longo prazo. Linfócitos Tfh específicos para SARS-CoV-2 são geradas durante a infecção aguda por SARS-CoV-2. Os anticorpos neutralizantes não estão ligados a redução da gravidade da COVID-19, mas linfócitos Tfh específicos contra o SARS-CoV-2 foram associadas à redução da gravidade da doença. (Meckiff et al., 2020).

A redução da linfopoiese provavelmente está relacionada a função das citocinas inflamatórias (IL-1 e IL-6) de direcionar a hematopoiese, concentrando para a síntese de células da linhagem mielóide, ocasionando a competição com a diferenciação de linfócitos ou até inibir sua ativação pelas células dendríticas. E assim os linfócitos atuantes tendem a exaustão e com a diminuição dos linfócitos TCD8 $8^{+}$, acarreta a diminuição da efetividade da resposta imune na eliminação do vírus, possibilitado o aumento da multiplicação viral e a intensidade do dano pulmonar. (Silva et al., 2021)

Em relação a resposta imune humoral, os antígenos primários examinados que levam a produção de anticorpos são as proteínas Spike e nucleocapsídeo. Os títulos de imunoglobulina G $(\mathrm{IgG})$ contra o nucleocapsídeo e a Spike estão altamente correlacionados (PICCOLI, et al., 2020). Spike é o alvo dos anticorpos neutralizantes contra o SARS-CoV-2, e o domínio de ligação ao receptor de Spike é o alvo de > 90\% dos anticorpos neutralizantes nos casos de COVID-19, com alguns anticorpos neutralizantes em vez de direcionar o domínio N-terminal (NTD). As estimativas de soroconversão para a proteína Spike 
variam de $91 \%$ a $99 \%$ em grandes estudos. Anticoorpos anti-Spike da classe $\operatorname{IgG}, \operatorname{IgA}$ e IgM se desenvolvem simultaneamente em indivíduos infectados. (WAJNBERG, et al., 2020). Em conjunto, o desenvolvimento de anticorpos neutralizantes contra SARS-CoV-2 é relativamente fácil, porque pode ser realizado por linfócitos B com pouca ou nenhuma maturação de afinidade necessária. Os dados também indicam que as respostas de anticorpos neutralizantes contra o SARS-CoV-2 geralmente se desenvolvem a partir de linfócitos B naive, não a partir de linfócitos B de memória reativa cruzada pré-existentes (Ng et al., 2020).

A relação entre anticorpos neutralizantes, linfócitos Tfh e a gravidade da COVID-19 parece ser complexa. Altos títulos de anticorpos neutralizantes estão associados a espectros graves da doença e as respostas dos linfócitos B potencialmente extra foliculares (PICCOLI, et al., 2021). Em contrapartida, os linfócitos Tfh específicos contra o SARS-CoV2 têm associações diferentes. Respostas de linfócitos T e B diferentes pode ocorrer devido a uma desconexão entre as respostas de linfócitos B e T à resposta imune inata precoce alterada, que pode resultar em atrasos cinéticos ou desregulação da iniciação dos linfócitos T. Para preencher essas lacunas de conhecimento, são necessários mais estudos longitudinais da cinética de anticorpos e respostas de linfócitos T específicos durante infecções agudas causadas por SARS-CoV-2 de gravidade variável. (Sette et al., 2021).

É desafiador interpretar a causa e o efeito imunológico em humanos, devido à natureza inerentemente correlativa dos dados, porém, a ausência de uma correlação entre os anticorpos neutralizantes e a recuperação do COVID-19 é notável. Dado que os linfócitos $\mathrm{TCD}^{+}$específicos para o SARS-CoV-2 e os linfócitos $\mathrm{TCD}^{+}$se correlacionaram com a redução da gravidade da doença, enquanto os anticorpos neutralizantes nos mesmos indivíduos não. Uma possível uma interpretação é que os linfócitos T fazem o trabalho pesado para o controle de uma infecção primária de SARS-CoV-2. (Gudbjartsson et al., 2021).

\section{Considerações Finais}

Nesta revisão bibliográfica, vimos as funções celulares relacionadas a infecção por SARS-CoV-2. Embora mais estudos sejam necessários, uma imagem começou a emergir revelando que os linfócitos TCD4+, os linfócitos TCD8+ e anticorpos neutralizantes contribuem para o controle de SARS-CoV-2 em ambos os casos não hospitalizados e hospitalizados de COVID-19.

As funções específicas e cinética da resposta imune adaptativa são discutidas, bem como sua interação com a imunidade inata e implicações para COVID-19. A mudança extrema no perfil de risco do COVID-19 entre os grupos de idade é provavelmente devida a vários fatores, pelo menos alguns dos quais não são imunológicos. No entanto, os dados disponíveis indicam que a fraca imunidade adaptativa ao SARS-CoV-2 é pelo menos um fator de risco para os idosos. Se as respostas lentas dos linfócitos TCD4+ são um fator de risco importante para COVID-19, essas células mostram-se um dos principais pontos fortes da imunização.

Para termos mais informaçãoes a respeito da resposta imunoligica ao SARS-CoV-2, acreditamos que a pesquisa em humanos pós vacina seja um fator importante para entender sobre as células principais, citadas acima. Tendo a partir desta revisão um ponto inicial de pesquisa.

\section{Agradecimentos}

Agredecemos primeiramente à nossa orientadora por ter aceitado o desafio deste projeto, por toda dedicação do seu escasso tempo e paciência durante todo o desenvolvimento.

Somos gratos aos nossos familiares que sempre estiveram ao nosso lado ao longo dos desafios enfrentados.

Também gostariamos agradecer à Universidade Anhembi Morumbi e a todos os professores do curso de Farmácia, pela elevada qualidade do ensino oferecido. 


\section{Referências}

Aid, M., Busman-Sahay, K., Vidal, S. J., Maliga, Z., Bondoc, S., Starke, C., Terry, M., Jacobson, C. A., Wrijil, L., Ducat, S., Brook, O. R., Miller, A. D., Porto, M., Pellegrini, K. L., Pino, M., Hoang, T. N., Chandrashekar, A., Patel, S., Stephenson, K., \& Bosinger, S. E. (2020). Vascular Disease and Thrombosis in SARS-CoV-2-Infected Rhesus Macaques. Cell, 183(5), 1354-1366.e13. https://doi.org/10.1016/j.cell.2020.10.005

Aoshi, T., Koyama, S., Kobiyama, K., Akira, S., \& Ishii, K. J. (2011). Innate and adaptive immune responses to viral infection and vaccination. Current Opinion in Virology, 1(4), 226-232. https://doi.org/10.1016/j.coviro.2011.07.002

Biochimica et Biophysica Acta (BBA) - Molecular Basis of Disease, 1866(10), 165878.

Brandão, S. C. S., Godoi, E. T. A. M., Ramos, J. D. O. X., Melo, L. M. M. P. D., \& Sarinho, E. S. C. (2020). COVID-19 grave: entenda o papel da imunidade, do endotélio e da coagulação na prática clínica. Jornal Vascular Brasileiro, 19

Ceravolo, M. G., Arienti, C., De Sire, A., Andrenelli, E., Negrini, F., Lazzarini, S., Patrini, M., Negrini, S., \& International Multiprofessional Steering Committee of Cochrane Rehabilitation REH-COVER action. (2020). Rehabilitation and Covid-19: the Cochrane Rehabilitation 2020 rapid living systematic review. European Journal of Physical and Rehabilitation Medicine. https://doi.org/10.23736/S1973-9087.20.06501-6

Gleichmann, N. (2020). Innate Vs Adaptive Immunity. From Technology Networks. https://www.technologynetworks.com/im munology/articles/innate-vsadaptive-immunity-335116

Gonçalves, Jonas Rodrigo (2021). Manual de artigo de revisão de literatura. / Jonas Rodrigo Gonçalves. - Brasília: Instituto Processus, (2021). (Coleção Trabalho de Curso, v. II). 3a edição 105 fls. Artigo de revisão. 2. ABNT. 3. Metodologia. II. Título.

Grifoni, A., Weiskopf, D., Ramirez, S. I., Mateus, J., Dan, J. M., Moderbacher, C. R., Rawlings, S. A., Sutherland, A., Premkumar, L., Jadi, R. S., Marrama, D., de Silva, A. M., Frazier, A., Carlin, A., Greenbaum, J. A., Peters, B., Krammer, F., Smith, D. M., Crotty, S., \& Sette, A. (2020). Targets of T cell responses to SARS-CoV-2 coronavirus in humans with COVID-19 disease and unexposed individuals. Cell, 181(7). https://doi.org/10.1016/j.cell.2020.05.015

Gudbjartsson, D. F., Norddahl, G. L., Melsted, P., Gunnarsdottir, K., Holm, H., Eythorsson, E., Arnthorsson, A. O., Helgason, D., Bjarn adottir, K., Ingvarsson, R. F., Thorsteinsdottir, B., Kristjansdottir, S., Birgisdottir, K., Kristinsdottir, A. M., Sigurdsson, M. I., Arnadottir, G. A., Ivarsdottir, E. V., Andresdottir, M., Jonsson, F., \& Agustsdottir, A. B. (2020). Humoral Immune Response to SARS-CoV-2 in Iceland. New England Journal of Medicine. https://doi.org/10.1056/nejmoa2026116

Lynch, K. L., Whitman, J. D., Lacanienta, N. P., Beckerdite, E. W., Kastner, S. A., Shy, B. R., Goldgof, G. M., Levine, A. G., Bapat, S. P., Stramer, S. L., Esensten, J. H., Hightower, A. W., Bern, C., \& Wu, A. H. B. (2020). Magnitude and kinetics of anti-SARS-CoV-2 antibody responses and their relationship to disease severity. Clinical Infectious Diseases. https://doi.org/10.1093/cid/ciaa979

Mahmudpour, M., Roozbeh, J., Keshavarz, M., Farrokhi, S., \& Nabipour, I. (2020). COVID-19 cytokine storm: The anger of inflammation. Cytokine, 155151. https://doi.org/10.1016/j.cyto.2020.155151

Meckiff, B. J., Ramírez-Suástegui, C., Fajardo, V., Chee, S. J., Kusnadi, A., Simon, H., Eschweiler, S., Grifoni, A., Pelosi, E. \& Weiskopf, D. (2020). Desequilíbrio de SARS-CoV-CoV-2- regulatório e citotóxico células T CD4 + reativas em COVID-19. Célula. 183: 1340-1353.e16

Naqvi, A., Fatima, K., Mohammad, T., Fatima, U., Singh, I. K., Singh, A., Atif, S. M., Hariprasad, G., Hasan, G. M., \& Hassan, M. I. (2020). Insights into SARS-CoV-2 genome, structure, evolution, pathogenesis and therapies: Structural genomics approach. Biochimica et biophysica acta. Molecular basis of disease, 1866(10), 165878. https://doi.org/10.1016/j.bbadis.2020.165878

Ng, K. W., Faulkner, N.., Cornish, G. H., Rosa, A., Harvey, R., Hussain, S., Ulferts, R., Earl, C., Wrobel, A. G. \& Benton, D. J. (2020). Preexisting and de novo humoral immunity to SARS-CoV-2 in humanos. Ciência. 370:1339-43

Oran, D. P., \& Topol, E. J. (2020). Prevalence of Asymptomatic SARS-CoV-2 Infection. Annals of Internal Medicine. https://doi.org/10.7326/m20-3012

Silva, César Augusto et al. Imunopatogênese no desenvolvimento da COVID-19. 102 p

V'kovski, P., Kratzel, A., Steiner, S., Stalder, H., \& Thiel, V. (2020). Coronavirus biology and replication: implications for SARS-CoV-2. Nature Reviews Microbiology, 19, 1-16. https://doi.org/10.1038/s41579-020-00468-6

Varnaitė 2020. (2020). Covid-19.Cochrane.org. https://covid-19.cochrane.org/studies/crs-14525219

Wajnberg, A., Amanat, F., Firpo, A., Altman, D. R., Bailey, M. J., Mansour, M., McMahon, M., Meade, P., Mendu, D. R., Muellers, K., Stadlbauer, D., Stone, K., Strohmeier, S., Simon, V., Aberg, J., Reich, D. L., Krammer, F., \& Cordon-Cardo, C. (2020). Robust neutralizing antibodies to SARS-CoV-2 infection persist for months. Science, 370(6521), 1227-1230. https://doi.org/10.1126/science.abd7728

World Health Organization. (2021). Coronavirus Disease (COVID-19). World Health Organization. https://www.who.int/health-topics/coronavirus\#tab=tab_1

Wu, T. (2020). Persistence of humoral and cellular immune response after SARS-CoV-2 infection: opportunities and challenges. Frontiers of Medicine. https://doi.org/10.1007/s11684-020-0823-4

Zhu, N., Zhang, D., Wang, W., Li, X., Yang, B., Song, J., Zhao, X., Huang, B., Shi, W., Lu, R., Niu, P., Zhan, F., Ma, X., Wang, D., Xu, W., Wu, G., Gao, G. F., \& Tan, W. (2020). A Novel Coronavirus from Patients with Pneumonia in China, 2019. New England Journal of Medicine, 382(8). https://doi.org/10.1056/nejmoa2001017 